\title{
Application of Schema Theory in High School English Reading Comprehension
}

\author{
Aijing Zhang \\ College of Teacher Education, Nanjing Normal University, Nanjing, China \\ Email address: \\ 2406231477@qq.com \\ To cite this article: \\ Aijing Zhang. Application of Schema Theory in High School English Reading Comprehension. Communication and Linguistics Studies. \\ Vol. 4, No. 2, 2018, pp. 32-36. doi: 10.11648/j.cls.20180402.12
}

Received: May 8, 2018; Accepted: May 30, 2018; Published: June 14, 2018

\begin{abstract}
Reading comprehension accounts for a lot in English tests. As a key and difficult point in English teaching at high school, the traditional way which focuses on the infusion of vocabulary and grammar may lead to decline of students' interest in English learning. It is important to find a suitable teaching method for high school students as soon as possible. The schema, which is also known as the background knowledge of students, plays a very essential role in their comprehension of reading materials. Therefore, this paper will concentrate on the exploration of schema theory to find out an English reading teaching method for high school English teachers, which can not only fundamentally improve the students' English grades, but also effectively transmit useful reading strategies to them and help them form a complete and comprehensive framework of knowledge. Rumelhart proposes that schema is consisted of several variables that represent elements of concepts, and it is a kind of knowledge framework and categorizing system. Based on this definition, this paper attempts to explain the relationship between the schema and the students' reading comprehension process, summarize the concrete role and important influence of the content schema, formal schema and language schema in English reading teaching, and verify the feasibility of the application of schema theory. And a detailed teaching method, which includes the English teaching process before, in and after class will be proposed.
\end{abstract}

Keywords: Schema Theory, Reading Comprehension in High School, Teaching Method

\section{Introduction}

\subsection{Reading and Reading Comprehension}

Reading is "the cognitive process of decoding symbols to derive meaning." [1] Zhang Biyin defines reading as the process of obtaining information from written material and then having influence on the non-intelligence factors of readers. [2] The reading process involves identification and comprehension. The writer first transfers his own ideas and feelings to his readers with linguistic symbols, then readers get stimulated by the linguistic symbols and begin to accept, imagine, modify, and understand what is transferred to him. And this is the process which endows meanings to the linguistic symbols. However, linguistic symbols always have a lot of different explanations, and they sometimes cannot explain certain abstract notions, therefore, the gap needs the readers' preexisting knowledge to compensate.

Reading is quite common in daily life, which is a way to share knowledge, transmit information and news, improve living standards and enrich people's feelings. However, in English language testing, there exists a term "reading comprehension", which is used to test the subjects' abilities to read with some questions to answer. It is a complex dynamic process of mental activities in which readers predict, sort out and make interpretations based on their prior knowledge, and then find the meanings of a text. Reading comprehension plays a very important role in English reading instruction and examination, involving both the mastery of vocabulary and grammar, and the proper application of certain reading strategies. Now, how to improve the efficiency of English reading comprehension and achieve the best result has been one of the most attractive topics for language teachers and researchers.

\subsection{Schema Theory}

\subsubsection{Development of Schema Theory}

In 1781, the German psychologist Kant first proposed the 
notion of "schema", which originally means the product of transcendental imagination, or the already acquired knowledge structure. Then, in 1932, the German modern psychologist Bartlett proposes in his Remembering: A Study in Experimental and Social Psychology that schema is the active combination of the previous response and experience. [4] Later, Rumelhart, an American expert in artificial intelligence, further advances Bartlett's theory. He thinks schema consists of several variables that represents elements of concepts, and it is a kind of knowledge framework and categorizing system. [5] In short, scholars from different fields have their different ideas for schema, which can help to explain and apply to the field they work for. Despite their different ideas, there is a common understanding that schema is a framework. It took almost 200 years to evolve and develop from the first conceptualization of schema to schema theory. And now, the modern schema theory points out that schema is a kind of unit which store the knowledge in mind. It is a kind of knowledge framework, and the sum of schema refers to all of the knowledge one possesses. [3]

The research of schema theory at home did not begin until 1980 when the theories are introduced to China. During this period, scholars in China, especially philosophers, mainly learnt from the findings abroad. And it was not until the 1990s that the theories began to be used and promoted to other areas, such as reading and translation. The approach of research is mostly dialectical, lacking practicability. From 2000 to now, researchers pay more attention to the application of schema theory, and experimental research starts and becomes more scientific and systematic. [6] The main fields concerned include cognitive science, psychology, philosophy, and foreign language teaching. The tendency of the research is that it has gradually centered on English teaching practice, but still experimental studies are inadequate, resulting in the lack of reliability and practical application.

\subsubsection{Application of Schema Theory in English Reading Comprehension}

The reading process can establish the framework of readers' background knowledge. They receive the information from texts, then perfect and correct their own schema. When schema is complete and concrete, it will be closer to the writer's intention, which will be helpful for the comprehension and absorption of the text. Just as pointed out by Goodman, reading is a "psycholinguistic guessing game" [7], the result of the interaction between linguistic knowledge and the world knowledge already integrated in the reader's mind.

In the late $1970 \mathrm{~s}$, schema theory was greatly influenced by the spread of computer science, information science and cybernetics. And the schema theory from then on is the modern schema theory, which is widely used to study the mental state of reading. As Zhang Fake and Wang Shunling said, the application of schema theory in foreign language reading instruction signs the new stage of the development of reading theories. [8] In 2003, Lu Zhongyi and Wang Zhe found from their experimental research that application of schema theory can improve their subjects' reading comprehension. [9] Two years later, Ma Junbo discussed about the possibility of the combination of schema theory with online ESP reading coursewares. [10] The research finds the significance of the application of schema theory to English reading comprehension.

However, the application of schema theory in English reading comprehension is now commonly used in college reading instruction, attempts at high school are rather rare. Besides, although there have been many articles underlining the importance of application of schema theory, questions such as how to put the proposed theory in actual teaching practice, and how to deal with the potential unexpected problems are still waiting to be solved. In addition, much attention has been paid to the widely accepted content schema, but the other two types, formal schema and language schema, are scarcely investigated.

All in all, there are still many problems to cope with, and in order to effectively put the theory into practice, there still needs further research.

\section{Relationship Between Schema and Teaching of English Reading}

The reading process, in essence, is constructing a certain kind of schema, and finding out continuously the implicit information in the text to concretize and modify the schema in readers' minds. When the schema in a reader's mind becomes complete and concrete, and keep approaching the writers' intention of writing, a full comprehension may be achieved. The schema theory can help students make predications, develop imagination, search memories, and modulate attention.

According to the schema theory of reading, there are three kinds of schema: formal schema, content schema and language schema. [11]

\subsection{Language Schema}

Language schema is the general knowledge of the linguistic rules of a particular language. It contains the background knowledge of the vocabulary, grammar, phonetic rules and so on. Without certain relevant language schema, the reader can hardly identify specific information in a text or take advantage of the information to activate the schema existing in the higher level of the mind and thus understand the text. That is to say, language schema plays a great role in reading comprehension. It is the basis of reading and the prerequisite of form and content schema.

When students have not mastered he required amount of vocabulary and knowledge of grammar, they are likely to find that most of the words in the given material are new, which will lead to his failure in reading comprehension, no matter how many reading skills and how much background knowledge he possesses. In the high school teaching of English reading, teachers should lead the students to analyze 
the long and difficult sentences, master more new words and grammar, in addition to the important words and phrases, so as to clear obstacles for their further reading.

\subsection{Content Schema}

Content schema refers to the "background knowledge of the content area of the text". It involves knowledge or information about what happens within a certain topic, and how these events relate to each other to form a coherent whole. It is the scope of the text's content, and it is the theme of the text, including some general and background knowledge such as the knowledge of a society. If the reader is short of some information related to the reading material, then there will not be an interplay with the reading content either, which means the reader's comprehension can not be complete or perfect. To begin with, it is the content schema that determines to what degree a student can comprehend the text. Sometimes, it can also help students overcome their vocabulary limitation, therefore, English teachers should pay attention to activate and complement the students' content schema. In addition, content schema is closely connected with the social environment, so it is necessary for English teachers to renew and update students' content schema in their minds. Only when they can keep up with the social development, can they take in the new and fresh ideas and knowledge successfully without misunderstandings. That is why so many aged people find it difficult to communicate with their next generations.

\subsection{Formal Schema}

Formal schema refers to the structure of a text, and generally means readers' knowledge of the genre and rhetorical devices. It is also crucial for the readers to understand the given text, because certain contents can only be expressed by certain corresponding forms or structures. When students are able to combine language schema with content schema, and apply the two kinds of schema to reading, they can understand what the text is talking about, but it is still hard for them to grasp the clear order of the text. There are fictions and nonfictions. There are 4 genres under fiction: novels, short stories, plays and poems. And under nonfiction, there are also 4 categories as well: description, narration, exposition and argumentation. A story is basically narration; a play is essentially interaction; a poem is meditation and the essential quality of nonfiction is persuasion. [12] Stories mainly contain such elements as character, plot, theme, setting and so on. While reading a story, the reader is supposed to recognize these elements and make out its major subject. Poems contain elements like rhyme, image, theme and so on, so reader should try to figure out the poet's feelings or ideas. To find out the logical order is very fundamental to understanding of an exposition. An argumentation consists of thesis, points and argument, which, to be fully understood, have to first be recognized.

In English reading class, teachers should help students get familiar with different genres and their specific features, so that students can figure out the general structure of the text successfully and have more correct and accurate understandings.

\section{Teaching Principles Within the Framework of Schema Theory}

Schema is closely related with students' reading process. However, the schema theory should never be abused, thus ignoring its actual realization in reading. When it is put into practice, there are some principles that should always be followed.

To begin with, schema should be combined with subject teaching. The traditional teaching method focus too much on teachers' infusion of vocabulary, sentences and grammar, and students' passive reception of these knowledge, thus turning a blind eye to the formation of appropriate schema in their minds. [13] But it is not advisable for English teachers to underline the formation of schema too much, and thus losing the balance between the schema and subject teaching, because without the support of grammar and vocabulary, schema can not work.

Secondly, guidance of English teachers should go together with autonomous learning of students. In traditional English class, students are always passively noting down what the teacher says, especially new words and phrases, and they seldom involve themselves in the class activities. But reading teaching under the direction of schema theory requires students to actively take in the stimulus or influence from outside and apply it to enrich his own schema. When students actively take part in the class, trying to talk about language rules, collecting and analyzing information, and cooperating with classmates, their learning process will further be advanced.

Finally, the sequential rule of schema will be observed. Of the three kinds of schema, language schema is prior to the formation of schema. And schema must first be activated and enriched before reading, and then it can be used during reading and reinforced after reading. That is to say, the application of schema involves a complete sequential process.

\section{Teaching Process Under the Direction of Schema Theory}

Schema theory can be applied to practice of reading teaching. Based on the analysis of several researchers and teaching experience of reading, a teaching method is proposed, suggesting what students and teachers can do before, in and after class and is hoped to improve their teaching and learning. [14]

\subsection{Before Class}

The schema that has existed in a student's mind is the basis of new knowledge acquisition. [15] Barnett once 
mentioned in his More Than Meets The Eye that English teachers have to design carefully their teaching plan to teach reading comprehension effectively. He further made an explanation of the pre-reading activities, maintaining that the activities must attract the students, provide relevant background information and activate necessary schema in their minds. [16] The pre-reading activities should guarantee students' reading appropriately at the beginning and then arouse students' interest in further reading. During this process, students must have access to independent exploration, and communicate and cooperate with each other. And to be detailed, teachers can activate students' schema through the following activities.

First, English teachers can help their students preview the text quickly. There are mainly two ways for readers to start reading. One is to read word by word without paying too much attention to what is told in the text, and the other is to spend a little time skimming the whole text, scanning a few sentences and making out what the writer intends to tell. A number of readers take the first way to read when they are not prepared for new words. Most of the time, they are likely to lose interest in reading because they find it uneasy to see new words and find it difficult to catch the main ideas. On the contrary, if readers have been aware of the writer's intention, they will know which information is important, practical or useful and then pay more attention to the key points. So, how can teachers help students preview the text? Teachers can ask students to finish reading in a limited time period. This can prevent students from reading word by word to some degree. In addition, students should be aware of the key words and important sentences. Furthermore, teachers can remind students to note and understand the title, subtitle, the first and the last paragraphs, the first and last sentences in each paragraph, forms and charts and so on in the text.

Second, teachers should introduce the background information and genre of the text to students. Background information is crucial for successful understanding of a text. English teachers are supposed to encourage students to look up to the information before the reading class. For example, when learning the Lost Civilization in Module 3 in the Advance with English, teachers can ask students to refer to the history of Pompeii and Loulan before the class. In addition to students' efforts, teachers can also show some relevant videos or pictures to make good preparations for teaching. Teachers mostly talk about genre in class, but as time is limited, they just discuss it briefly, which will leave a little impression on students. However, genre is rather important as the representation of form schema. Barnett believed that once a student realize a genre that he has already known, many new words and even sentence structures would be easy. Investigation of form schema shows, readers' knowledge of the genre and construction can be helpful for their successful understanding. At the beginning, teachers can lead students to identify the genre, and when the students are familiar with genre, teachers are supposed to remove the support and give students chance to practice.

Third, before reading, teachers can guide students to predict the form and content of the text. Positive prediction should be involved in the reading process. But prediction is not always reliable and accurate, and should be tested and supported by further reading. According to Qi Qi and Li Luping, good readers often make prediction of the text's form and content before reading, which can help them monitor their reading process, keep their attention on key points and connect what is available in the text intentionally with what they have already known. In other words, prediction can help activate their schema, and the activated schema can later be reinforced and complemented in turn from new information. [17]

\subsection{In Class}

The reading class is most important for improving students' reading comprehension. In an English reading class, students' schema should be invoked and enriched, so as to help students take both a bird's eye view and a worm's eye view of the whole text. Before the class, students have made some predictions, so in class they should test the validity and accuracy of their hypothesis. With modifications and correctness, they gradually approach the true intention of the writer and grasp the major ideas expressed by the writer.

There are two steps for the teacher to guide students to read: fast reading and careful reading. In the first step, English teachers can provide some attractive and meaningful questions that can either activate students' schema and encourage their imagination or lead them to the ideas and themes of the text. Skimming and scanning strategies are very useful in this step. Formal schema is mainly invoked to promote students to find out the genre, structure or form. Besides, English teachers should discuss with the students about rules of each genre and laws of answering questions. In the second step, what really matters is the details entailed in the text to master the main contents and perfect their schema. During this process, teachers can design various kinds of activities to achieve the purposes above. For example, assign some multiple questions, gap fillings, short answer questions according to the implicit information. With these activities, students' abilities to locate, analyze and synthesize information will be trained. Also, old schema and new schema will confront, contradict and coalesce with each other.

\subsection{After Class}

After pre-reading and reading, the students usually have known a lot about the contents of the text. And it is necessary to review and consolidate what has been taught in time. Activities such as retelling, imitation, after-class discussion will be of importance for the students to internalize the knowledge. English teachers can use language schema to help students review new words, syntax and grammar; they can use content schema to help review the details and concrete information, and thus enriching or 
further exploring the background knowledge; they can also use formal schema to generalize the genres and relevant reading skills and strategies. In addition to review, frequent practice is also crucial to help make the cognitive schema become automatic. Teachers should evaluate students' learning appropriately, giving feedback in time to help students correct themselves. And students should also have the chance to communicate about their learning and make self-evaluations and evaluations for others, so that they can make positive adjustment.

To put it in a nutshell, the three kinds of schema: language schema, formal schema and content schema are closely connected with the reading process, and the schema theory can be put into practice to teach reading. With its guidance, teachers are supposed to lead students to preview and predict the text before class. Then, they can teach with fast reading first and then careful reading in class. Fast reading is used to help students be familiar with the main ideas, while careful reading can help students find out some important details in the text. After class, teachers ought to pay their attention to students' review and evaluation, which is helpful for adjustment and consolidation.

\section{Conclusion}

The thesis tries to address the application of schema theory in high school English teaching of reading comprehension. With review of the research of reading and schema theory in China and other countries, and exploring the connection between three kinds of schema and reading process, a model of teaching reading is proposed, though not tested. Now, the society demands for those intellects with comprehensive abilities to collect and analyze data and information effectively. Therefore, the application of schema theory in teaching can meet the social needs. It can help free students and teachers from the constraint of vocabulary and grammar, and direct their attention to the long-term reading process and experience. Under the guidance of rich background knowledge, some obstacles students used to meet can be overcome. Besides, when students are equipped with certain reading skills and answering strategies, their grades will be improved. What's more, as the efficiency of reading advanced, students will gradually develop their own styles of reading, and at that time reading cannot be a challenge or even a disaster, but what they are interested in. And interest will promote their reading skills and strategies again.

\section{References}

[1] Michel, De Certeau. Reading as Poaching [M]. Trans. Steven F. Rendall, 1984.

[2] Zhang Biyin. Reading Psychology [M]. Peking University Press, 1992.

[3] Lei Xiaodong. Conceptual Fluency and Schema Theory [J]. Journal of Shanxi Normal University (Social Science Edition), 2010.

[4] Bartlett, Frederic. Remembering: A Study in Experimental and Social Psychology [M]. Cambridge University Press, 1932.

[5] Rumelhart, David Everett. \& McClelland, James. Parallel Distributed Processing: Explorations in the Microstructure of Cognition [M]. La Jolia, 1986.

[6] Kang Lixin. A Review of Domestic Schema Theory. [J]. Henan Social Sciences, 2011.

[7] Goodman, K. S. Reading: A Psycholinguistic Guessing Game [J]. Foreign Language Teaching Abroad, 1983.

[8] Zhang Fake; Wang, Shunling. The Application of the Schema Theory to the teaching of EFL Reading__ Teaching of the Integrated Course as a Case [J]. Foreign Language World, 2010 .

[9] Lu Zhongyi and Wang Zhe. An Experimental Study of the Influence of the Schema Training of English Argumentation on Reading Comprehension [J]. Foreign Language Teaching and Research, 2003.

[10] Ma Junbo. The Comprehensive Application of Case Teaching and Schema Theory in ESP Reading Network Courseware [J]. Media in Foreign Language Instruction, 2005.

[11] Carrell, Patricia. \& Eisterhold, Joan. Schema Theory and ESL Reading Pedagogy [J]. Tesol Quarterly, 1983.

[12] Shao Jindi and Bai Jingpeng. Introduction to Literature [M]. Shanghai Foreign Language Education Press, 2011.

[13] Discourse Analysis, Schema Theory and English Reading Teaching [J]. New Curriculum Research, 2016.

[14] Zhou tinghua and Jiang Caili. Teaching Design of High School English Reading Course Based on Schema Theory [J]. English Teachers, 2017.

[15] Cooper, Graham. \& Sweller, John. Effects of Schema Acquisition and Rule Automation in Mathematical Problem-Solving Transfer [J]. Journal of Educational Psychology, 1987.

[16] Barnett, Marva. More Than Meets The Eye [M]. New Jersey Prentice Hall Regents, 1989.

[17] Qi Qi and Li Luping. Schema Theory and Pre-reading Teaching Activities. [J]. Journal of Capital Normal University, 1999. 